\title{
CHILDHOOD VITILIGO: A RETROSPECTIVE CLINICO-EPIDEMIOLOGICAL STUDY
}

\author{
Ahmed Abdul-Aziz Ahmed ${ }^{1}$, Hayder Saad Ahmed ${ }^{1}$, Mustafa Hameed Mohammed,', \\ Mohammed Shanshat \\ ${ }^{1}$ Department of Dermatology and Venereology, College of Medicine, Tikrit University, Iraq. \\ ${ }^{2}$ Department of Dermatology and venerology, Salah Al-Din Hospital, Iraq. \\ ${ }^{3}$ Department of Dermatology and Venereology,Baghdad Teaching Hospital, Baghdad, Iraq.
}

\section{Corresponding author:}

Hayder Saad Ahmed, Lecturer, Dermatology and Venereology Department, College of Medicine, Tikrit University, Salah AI-Din, Iraq. Postal code: 34001; Email: haidersaad@tu.edu.iq; ORCID ID: https://orcid.org/0000-0003-1367-4461

\section{ABSTRACT}

Background: Vitiligo is an acquired depigmentary disorder of the skin, mucous membrane and hair follicle resulting from selective destruction of melanocytes.

Aims of Study: Identify the clinico-epidemiological characteristics of childhood vitiligo.

Patients and Methods: A retrospective study carried out at the dermato-venereology clinic of Salah Al-Din Hospital. A total of 120 vitiligo patients, all younger than 17 years old, were enrolled.

Results: Among included patients, (40\%) were male and (60\%) were female (M:F=2:3). The mean age of onset was (11.5 \pm 6.4 years) with (60.8\%) of patients were (11-17) years old, $(25 \%)$ were (6-11) years and (14.2\%) were (0-5) years old. Majority of patients were from urban area (87.5\%). Generalized types of vitiligo account for (56.7\%) besides (22.5\%), (17.5\%) and (3.3\%) represented focal, acrafacial and segmental vitiligo, respectively. Only (8.3\%) have nail changes, presented as longitudinal ridging followed by leukonychia. Family history was positive in 
medRxiv preprint doi: https://doi.org/10.1101/2020.09.16.20195636; this version posted September 18, 2020. The copyright holder for this preprint (which was not certified by peer review) is the author/funder, who has granted medRxiv a license to display the preprint in perpetuity. All rights reserved. No reuse allowed without permission.

(37.5\%) of vitiligo patients. Treatment used for vitiligo were topical corticosteroids (92.5\%), topical calcineurin inhibitors (55\%), NB-UVB (84.2\%), and systemic steroids (30.8\%).

Conclusions: Majority of childhood vitiligo develops after puberty and predominantly affects female. Generalized vitiligo is the most frequent type. Atopic dermatitis is the most common associated disease.

Key words: Childhood vitiligo, atopic dermatitis, epidemiology, longitudinal ridging. 
medRxiv preprint doi: https://doi.org/10.1101/2020.09.16.20195636; this version posted September 18, 2020. The copyright holder for this

\section{Introduction}

Vitiligo is a non-contagious depigmentary disorder that is almost always acquired. It presents as depigmented well defined ivory white macules and patches of different configuration and variable size with unpredictable disease coarse. It may have a generalized, acrofacial, segmental or focal distribution. Selective destruction of melanocytes due to autoimmune mechanisms, intrinsic melanocyte defects or oxidative stress represent possible pathogenic mechanisms. ${ }^{1}$

Worldwide, the prevalence of vitiligo is $1-2 \%$ with more than $50 \%$ of patients having a childhood onset. Gender distribution among patients shows slight female predominance in childhood vitiligo compared to almost equal prevalence among adults with vitiligo. ${ }^{2}$

Distribution of vitiligo lesions varies among pediatric patients and most frequently presents as generalized disease in $34 \%$ followed by acrofacial in $13 \%$, mucosal in $3 \%$, segmental in $29 \%$, and undetermined in $21 \% .^{3}$

Childhood vitiligo may cause significant psychological consequences for the patients, causing depression, anxiety, lower self-esteem, and poor quality of life.Anxiety and depression were observed in $26-42 \%$ in parents of childhood vitiligo. ${ }^{4}$

Vitiligo is associated with several autoimmune diseases, particularly thyroid disease, pernicious anemia, atopic dermatitis, diabetes mellitus and alopecia areata. ${ }^{5}$ There are several treatment modalities for vitiligo. Topical corticosteroid as currently the first line treatment except for facial and genital vitiligo were topical calcineurin inhibitors are preferred initially. Different types of phototherapy are available with narrow band UVB (NB-UVB) considered safe and highly effective for widespread childhood vitiligo. Systemic immuomodulators and immunosuppressives are used for rapidly progressive disease to achieve rapid control, particularly systemic corticosteroids; however, their use should be limited to a short duration to avoid undesirable side effects. ${ }^{6}$ 
medRxiv preprint doi: https://doi.org/10.1101/2020.09.16.20195636; this version posted September 18, 2020. The copyright holder for this

\section{Patients and Methods}

This work is a retrospective observational study carried out at the outpatient clinic of Salah alDin Hospital in Iraq. A total number of 120 patients with clinical diagnosis of vitiligo were selected between November 2019 and May 2020. Patients older than 17 years old were excluded.

The age, gender, residence and clinical distribution of vitiligo were recorded for all patients included in the study. Data were analyzed using SPSS version 20. A chi-square and fisher exact test were used to test statistical significance with a P-value of $<0.05$ was considered as statistically significant.

Regarding ethical consideration, the study was approved by Salah al-Din health directorate, ministry of health, Iraq. Verbal informed consent was taken from all included patients. In addition, all data was kept confidential apart from the purpose of the study.

\section{Results}

Regarding demographic data of patients, females were affected more than males, 60\% ( $n=72$ ) and $40 \%(n=48)$, respectively, with a male to female ratio of 2:3 ( $p$-value $>0.05$ ). Majority of patients $87.5 \%(n=105)$ were from urban region in contrast to $12.5 \%(n=15)$ were from rural area. Table 1

The age range was 3-17 years old with the mean age of onset was $11.5 \pm 6.4$ years. The frequency of patients between $11-17$ years old was $60.8 \%$ ( $n=73)$ with $25 \%(n=30)$ of patients were between 6-10 years and only 14.2\% ( $n=17)$ less than 5 years old. Table 2

The study showed that generalized vitiligo $56.7 \%(n=68)$ was the most prevalent clinical patten of vitiligo. Focal and acrafacial vitiligo reported in $22.5 \%(n=27)$ and $17.5 \%(n=21)$, respectively. Segmental vitiligo represented the least common type 3.3\% (n=4). In addition, the trunk $46.7 \%$ $(n=56)$ was most frequently affected site followed by the head and neck region $33.3 \%(n=40)$ while genital and acral sites represented $2.5 \%(n=3)$ and $17.5 \%(n=21)$, respectively. Table 3 
medRxiv preprint doi: https://doi.org/10.1101/2020.09.16.20195636; this version posted September 18, 2020. The copyright holder for this

Seventy eight percent $(n=84)$ of patients have no nail findings. However, longitudinal ridging was recorded in $8.3 \%(n=10)$ and was most prevalent among females. In contrast, leukonychia was observed in $5 \%(n=6)$ which was exclusively reported in males $(p<0.05)$. Table4

Regarding family history of vitiligo, it was negative in $62.5 \%(n=75)$ of patients while $37.5 \%$ $(n=45)$ reported having a positive family history of vitiligo. In addition, $87.5 \%(n=105)$ of patients have no family history of other autoimmune diseases except for psoriasis $5.8 \%(n=7)$, thyroid disease $4.2 \%(n=5)$ and alopecia areata $2.5 \%(n=3)$. Table5

Negative past medical history of childhood vitiligo was observed in $75.8 \%(n=91)$. Atopic dermatitis was the most frequent associated disorder presented in $7.5 \%(n=9)$ followed by autoimmune anemia in $5.8 \%(n=7)$ and koebner phenomena in $4.2 \%(n=5)$. Each of the following disorders, diabetes mellitus, autoimmune thyroiditis, alopecia areata and halo phenomena, was observed in $1.6 \%(n=2)$. Table6

Different modalities were used for the treatment of childhood vitiligo. The study showed $92.5 \%$ $(n=111)$ of patients used topical steroids and $55 \%(n=66)$ used topical calcineurin inhibitors. UVB was used in $84.2 \%(n=101)$. In addition, $30.5 \%(n=37)$ of patients used systematic steroids. Females used all types of medical treatments more frequently than males. Table 7 
Table 1: Demographic data of childhood vitiligo.

\begin{tabular}{|l|c|c|}
\hline Gender & Frequency & Percent \% \\
\hline Female & 72 & $60 \%$ \\
\hline Male & 48 & $40 \%$ \\
\hline Total & 120 & $100 \%$ \\
\hline Residence & Frequency & Percent \% \\
\hline Urban & 105 & $87.5 \%$ \\
\hline Rural & 15 & $12.5 \%$ \\
\hline Total & 120 & $100 \%$ \\
\hline
\end{tabular}

Table 2: Age of onset of childhood vitiligo in both genders.

\begin{tabular}{|l|l|c|c|c|}
\hline Age of onset (years) & & Female & Male & Total \\
\hline $\mathbf{0 - 5}$ & No. & 13 & 4 & 17 \\
\hline $\mathbf{6 - 1 0}$ & $\%$ & $10.8 \%$ & $3.3 \%$ & $14.2 \%$ \\
\hline & No. & 18 & 12 & 30 \\
\hline $\mathbf{1 1 - 1 7}$ & $\%$ & $15 \%$ & $10 \%$ & $25 \%$ \\
\hline & No. & 41 & 32 & 73 \\
\hline Total & $\%$ & $34.2 \%$ & $26.7 \%$ & $60.8 \%$ \\
\hline & No. & 72 & 48 & 120 \\
\hline & $\%$ & $60 \%$ & $40 \%$ & $100 \%$ \\
\hline & Pearson Chi-Square= 2.36a & p-value $=\mathbf{0 . 3 0 6}$ & \\
\hline
\end{tabular}


Table 3: Patterns and distribution of childhood vitiligo in both genders

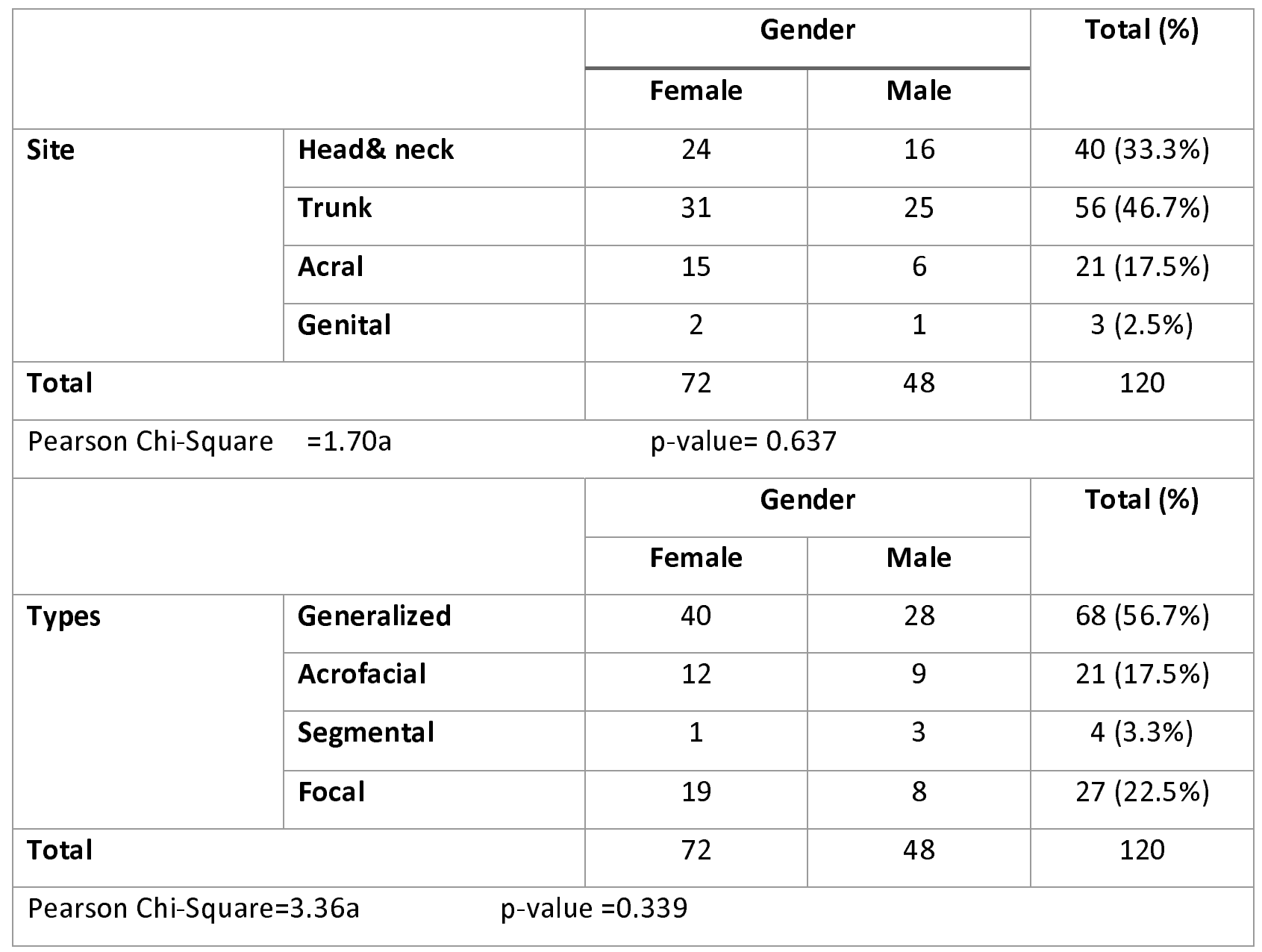

Table 4: Nail findings in childhood vitiligo.

\begin{tabular}{|c|c|c|c|c|}
\hline & & \multicolumn{2}{|c|}{ Gender } & \multirow[t]{2}{*}{ Total (\%) } \\
\hline & & Female & Male & \\
\hline \multirow[t]{3}{*}{ Nail finding } & Negative & 66 & 38 & $104(86.7 \%)$ \\
\hline & Longitudinal ridging & 6 & 4 & $10(8.3 \%)$ \\
\hline & Leukonychia & 0 & 6 & $6(5 \%)$ \\
\hline \multicolumn{2}{|l|}{ Total } & 72 & 48 & 120 \\
\hline Pearson Chi-Square & \multicolumn{4}{|c|}{$p$-value $=0.008$} \\
\hline
\end{tabular}


Table 5: Family history of autoimmune diseases associated with childhood vitiligo.

\begin{tabular}{|c|c|c|c|c|}
\hline & & \multicolumn{2}{|c|}{ Gender } & \multirow[t]{2}{*}{ Total (\%) } \\
\hline & & Female (\%) & Male & \\
\hline \multirow{2}{*}{$\begin{array}{l}\text { Family history of } \\
\text { vitiligo }\end{array}$} & Negative & 47 & 28 & $75(62.5 \%)$ \\
\hline & Positive & 25 & 20 & $45(37.5 \%)$ \\
\hline \multicolumn{2}{|l|}{ Total } & 72 & 48 & 120 \\
\hline \multicolumn{2}{|c|}{ Pearson Chi-Square $=0.59 \mathrm{a}$} & $p$-value $=0.41$ & & \\
\hline \multirow{2}{*}{\multicolumn{2}{|c|}{ Family history of autoimmune diseases }} & \multicolumn{2}{|c|}{ Gender } & Total (\%) \\
\hline & & Female & Male & \\
\hline \multirow[t]{4}{*}{ Family history } & Negative & 64 & 41 & $105(87.5 \%)$ \\
\hline & Psoriasis & 4 & 3 & $7(5.8 \%)$ \\
\hline & Thyroid disorders & 3 & 2 & $5(4.2 \%)$ \\
\hline & Alopecia areata & 1 & 2 & $3(2.5 \%)$ \\
\hline \multicolumn{2}{|l|}{ Total } & 72 & 48 & 120 \\
\hline \multicolumn{5}{|c|}{ Pearson Chi-Square $=0.55 a \quad p$-value $=0.813$} \\
\hline
\end{tabular}


Table 6: Past medical history in patients with childhood vitiligo.

\begin{tabular}{|c|c|c|c|c|}
\hline & & \multicolumn{2}{|c|}{ Gender } & \multirow[t]{2}{*}{ Total (\%) } \\
\hline & & Female & Male & \\
\hline \multirow[t]{8}{*}{ Past-medical history } & Negative & 57 & 34 & $91(75.8 \%)$ \\
\hline & Diabetes mellitus & 1 & 1 & $2(1.6 \%)$ \\
\hline & Thyroid disorders & 1 & 1 & $2(1.6 \%)$ \\
\hline & $\begin{array}{l}\text { Autoimmune } \\
\text { Anemia }\end{array}$ & 4 & 3 & $7(5.8 \%)$ \\
\hline & Alopecia areata & 0 & 2 & $2(1.6 \%)$ \\
\hline & Atopy & 4 & 5 & $9(7.5 \%)$ \\
\hline & $\begin{array}{l}\text { Koebner } \\
\text { phenomena }\end{array}$ & 3 & 2 & $5(4.2 \%)$ \\
\hline & Halo phenomena & 2 & 0 & $2(1.6 \%)$ \\
\hline \multicolumn{2}{|l|}{ Total } & 72 & 48 & 120 \\
\hline \multicolumn{2}{|c|}{ Pearson Chi-Square $=5.65 \mathrm{a}$} & $=0.559$ & & \\
\hline
\end{tabular}


Table 7: Treatment modalities for childhood vitiligo in both genders.

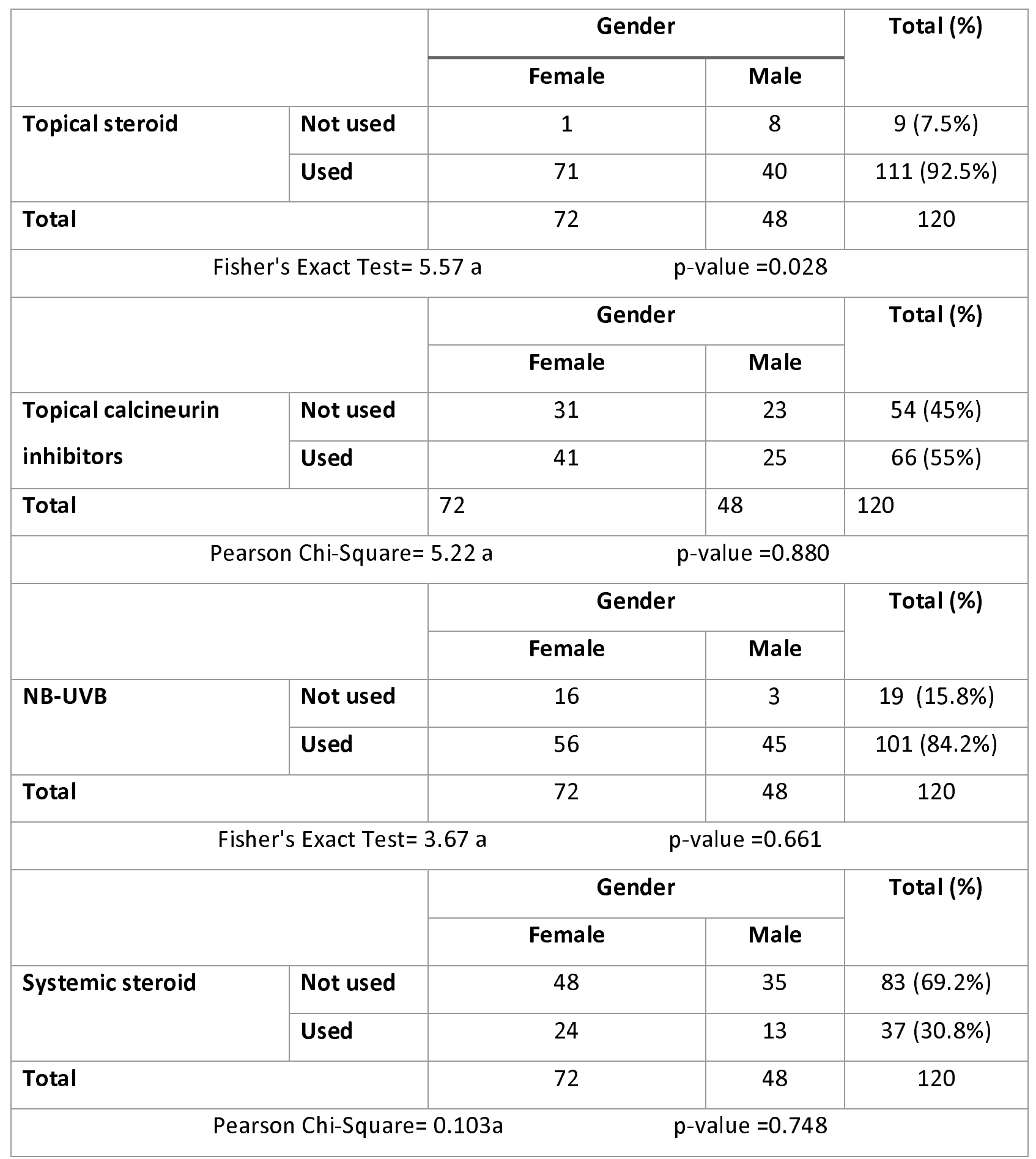


medRxiv preprint doi: https://doi.org/10.1101/2020.09.16.20195636; this version posted September 18, 2020. The copyright holder for this

\section{Discussion}

Vitiligo is considered the most common acquired cutaneous depigmentary disease with unpredictable course that is usually associated with significant psychological consequences. ${ }^{1}$ Different studies have demonstrated the increased risk of several autoimmune diseases in patients with vitiligo, particularly diabetes mellitus, thyroid disorders, alopecia areata, psoriasis, and pernicious anemia. ${ }^{5}$

Despite vitiligo was reported to affects both genders in equal proportions in adults and sometimes in children ${ }^{7}$, childhood vitiligo tends to affect females more frequently than males. ${ }^{6}$ A study by El-Husseiny R et al. $2020^{8}$ involving 483 child with vitiligo observed that females were affected in $59.1 \%(n=130)$ of patients. In addition, similar results were observed by Shajil et al. $2006^{9}$ and Nunes \& Esser $2011^{10}$. These findings agree with results observed in this study were females represented $(60 \%)$ of patients. Females are more emotionally fragile to cosmetically disfiguring and socially stigmatizing nature of vitiligo than males. Nevertheless, the role genetic factors and environmental triggers, in addition to the influence of female hormones, should also be considered as possible causes of female dominance.

Several studies have subdivided childhood vitiligo into different age groups. The most common age group reported in this study was 11-17 years old. Kanwar et al. ${ }^{11} 2005$ and Brazzelli $V$ et al. $^{12} 2005$ made similar observations. This indicate that more than half of childhood vitiligo develop after puberty which is possibly related to the hormonal changes during this period, particularly in females. However, a study by Gupta M. et al. ${ }^{13}$ in 2018 involving 50 patients with childhood vitiligo reported ( 5.6 years)as the mean age of onset.

Vitiligo presents clinically in different patterns. A study by Ali A. et al. ${ }^{14} 2011$, enrolling 38 child with vitiligo, recognized generalized vitiligo $44.7 \%(n=17)$ as the most common type followed by acrofacial $26.3 \%(n=10)$, focal $26.3 \%(n=10)$, and segmental vitiligo $2.6 \%(n=1)$, an observation consistent with the results of Liu JB. et al. ${ }^{15} 2005$ and Zhang Z. et al. ${ }^{16} 2009$. In this study, results showed that generalized vitiligo $56.7 \%(n=68)$ and segmental vitiligo $3.3 \%(n=4)$ agree with the above mentioned studies; however, focal vitiligo $22.5 \%(n=27)$ was more common than acrofacial vitiligo $17.5 \%(n=21)$. 
medRxiv preprint doi: https://doi.org/10.1101/2020.09.16.20195636; this version posted September 18, 2020. The copyright holder for this

Different studies are contradicted regarding the most common sites affected by vitiligo. The results of this study revealed that the trunk is most common affected site $46.7 \% \quad(n=56)$, followed by the head and neck region in $33.3 \%(n=40)$ of patients. The acral sites were affected in $17.5 \%(n=21)$ with only $2.5 \%(n=3)$ of patients have genital lesions. These results contradicted with a study conducted by Ranaivo Irina, et al. ${ }^{17} 2019$ involving 64 child with vitiligo (24.7\% in head and $19.1 \%$ in trunk). In addition, Sheth et al. $2015^{18}$ reported that the lower limbs was most frequently involved (62\%) followed by the face (46\%), the upper limbs (30\%), the scalp (25\%), and the mucosa (18\%).Similar observations were also made by Gupta M. et al. ${ }^{13} 2018$.

We reported nail lesions to occur in $13.3 \%(n=16)$ of patients presenting as longitudinal ridging $8.3 \%(n=10)$ and as leukonychia 5\% (n=6). Topal IO et al. ${ }^{19} 2016$ conducted a case control study enrolling 100 patient with vitiligo, has also observed longitudinal ridging as the most common nail abnormality 42\% ( $n=42$ ) associated with vitiligo ( $p$ value=0.001). In addition, he reported that more than two third $78 \%(n=78)$ of patients has at least one nail abnormality. However, his study involved vitiligo in all age group.

The incidence of positive family history in vitiligo patients is $11-46 \%$ as reported by different studies. ${ }^{20}$ In the current study, positive family history of vitiligo was observed in $37.8 \%$ ( $n=45$ ) of childhood vitiligo. A similar observation was made by Lahlou A. et al. ${ }^{21} 2017$ who reported 39\% $(n=12)$ of patients have a family history of vitiligo. A positive family history highlights the role of genetic factors in developing vitiligo, particularly in this country, due to the high incidence of consanguineous marriage.

The prevalence of associated autoimmune diseases in childhood vitiligo are variable among different studies. Autoimmune thyroid disorders are the most commonly reported in association with vitiligo (12.9\%). In contrast, the present study revealed that atopic dermatitis is the most common associated disease $7.5 \%(n=9)$ followed by anemia $5.8 \%(n=7)$. In addition, alopecia areata was observed in $2.5 \%(n=2)$ of this study which is more than double what was observed by Al-Mutairi $\mathrm{N}$ et al. ${ }^{22}$ in 2005 were alopecia areata reported in $1.1 \%(n=1)$, and by Handa S et al. ${ }^{23}$ in 2003 were $1.3 \%(n=2)$ of patients have alopecia areata. Koebner phenomena, 
medRxiv preprint doi: https://doi.org/10.1101/2020.09.16.20195636; this version posted September 18, 2020. The copyright holder for this

as a marker of disease activity, was reported by Agarwal S et al. ${ }^{3}$ in 2013 to occur in $24.3 \%$ $(n=66)$ of patients with childhood vitiligo compared with $4.2 \%(n=5)$ in the present study.

Topical corticosteroids are are considered the first line treatment for limited vitiligo, $<20 \%$ of body surface area ${ }^{6}$, explaining its use by $92 \%(n=111)$ of patients in this study. Several studies have shown that topical corticosteroids is moderately effective to induce repigmentation of vitiligo. $^{24}$ The high response rate, ease of application, high rate of compliance, and low cost are the advantages of topical corticosteroid therapy for vitiligo. On the other hand, topical calcineurin inhibitors are particularly useful and effective treatment for facial and genital lesions to avoid the side effects of corticosteroids in these regions. Studies by Silverberg et al $^{25}$ 2004 and by Kanwar et $\mathrm{al}^{26} 2004$ demonstrated the efficacy of topical tacrolimus use for vitiligo. It was used by $55 \%(n=66)$ of children in the present study.

NB-UVB therapy offers the advantage of being safe in children, no need for photosensitizing agent, and not associated with ocular complications. NB-UVB was used in $84 \%(n=101)$ of patients in this study. Kumar $\mathrm{Y} \mathrm{H}$ et al. ${ }^{27} 2015$ have demonstrated the efficacy of NB-UVB in childhood vitiligo with $76.8 \%(n=22)$ of patients achieved complete repigmentation and $14.2 \%$ $(n=4)$ achieved partial repigmentation among a total of 28 patients.

Systemic therapy by short course of steroid may be required for rapidly progressive vitiligo either as oral or parenteralroutes. ${ }^{6}$ In this study, only $30 \%(n=37)$ of patients used systematic steroids. A study conducted by Majid let al. ${ }^{28} 2009$ demonstrated that mini-pulse oral methylprednisolone is effective in halting the progression of vitiligo in $90 \%$ of patients with rapidly progressive disease.

There are few limitations to this study. The duration of this study was relatively shorts to collect large sample size which considered relatively small. In addition, being a single center study is also considered a limitation. However, due to the pandemic of COVID-19, the lockdown of the city and shifting most medical facilities against corona virus, patients faced difficulties access medical care for their vitiligo.

\section{Conclusion}


medRxiv preprint doi: https://doi.org/10.1101/2020.09.16.20195636; this version posted September 18, 2020. The copyright holder for this

Childhood vitiligo affects female more than males. The generalized pattern is the most frequent type and mostly affects the trunk. Atopic dermatitis was the most common associated disease while longitudinal ridging is the predominant nail findings in childhood vitiligo.

\section{Compliance with Ethical Standards}

Funding: No funding was received from any source.

Conflict of Interest: All authors (Mohammad S.Nayaf, Ahmed Abdul-Aziz Ahmed, Hayder

Saad Ahmed, Wisam S. Najim) declare that they have no conflict of interest.

\section{Ethical Approval:}

- All procedures performed were in accordance with the ethical standards of the institutional and/or national research committee and with the 1964 Helsinki declaration and its later amendments or comparable ethical standards.

- This article does not contain any studies with animals performed by any of the authors.

Informed Consent: Informed consent was obtained from all individual participants included in the study.

\section{References}

1. Manzoni AP, Weber MB, NagatomiAR et Al. Assessing depression and anxiety in the caregivers of pediatric patients with chronic skin disorders. An Bras Dermatol. 2013; 88(6):894-9.

2. Yamamah GA, Emam HM, Abdelhamid MF, Elsaie ML, Shehata H, Farid T, Kamel MI, Taalat AA. Epidemiologic study of dermatologic disorders among children in South Sinai, Egypt. International journal of dermatology. 2012 Oct;51(10):1180-5.

3. Agarwal S, Gupta S, Ojha A, Sinha R. Childhood vitiligo: clinicoepidemiologic profile of 268 children from the Kumaun region of Uttarakhand, India. Pediatric dermatology. 2013 May;30(3):348-53.

4. Ramien ML, Ondrejchak S, Gendron R, Hatami A, McCuaig CC, Powell J, Marcoux D. Quality of life in pediatric patients before and after cosmetic camouflage of visible skin conditions. Journal of the American Academy of Dermatology. 2014 Nov 1;71(5):935-40. 
medRxiv preprint doi: https://doi.org/10.1101/2020.09.16.20195636; this version posted September 18, 2020. The copyright holder for this

5. Gill L, Zarbo A, Isedeh P, Jacobsen G, Lim HW, Hamzavi I. Comorbid autoimmune diseases in patients with vitiligo: a cross-sectional study. Journal of the American Academy of Dermatology. 2016 Feb 1;74(2):295-302.

6. Gianfaldoni S, Wollina U, Tchernev G, Lotti J, França K, Lotti T. Vitiligo in Children: A Review of Conventional Treatments. Open Access Maced J Med Sci. 2018 Jan 25; $6(1): 213-217$.

7. Hu Z, Liu JB, Ma SS, Yang S, Zhang XJ. Profile of childhood vitiligo in China: an analysis of 541 patients. Pediatric dermatology. 2006 Mar;23(2):114-6.

8. El-Husseiny R, Abd-Elhaleem A, Salah El-Din W, Abdallah M. Childhood vitiligo in Egypt: Clinico-epidemiologic Profile of 483 patients. Journal of Cosmetic Dermatology. 2020 Apr 22.

9. Shajil EM, Agrawal D, Vagadia K, Marfatia YS, Begum R. Vitiligo: clinical profiles in Vadodara, Gujarat. Indian Journal of Dermatology. 2006 Apr 1;51(2):100.

10. Nunes DH, Esser LM. Vitiligo epidemiological profile and the association with thyroid disease. Anais Brasileiros de Dermatologia. 2011 Apr;86(2):241-8.

11. Kanwar AJ, Dogra S. Narrow-band UVB for the treatment of generalized vitiligo in children. Clinical and Experimental Dermatology: Clinical dermatology. 2005 Jul;30(4):332-6.

12. Brazzelli V, Prestinari F, Castello M, Bellani E, Roveda E, Barbagallo T, Borroni G. Useful treatment of vitiligo in 10 children with UV-B narrowband (311 nm). Pediatric dermatology. 2005 May;22(3):257-61.

13. Gupta M. Childhood vitiligo: A clinicoepidemiological study. Indian Journal of Paediatric Dermatology. 2018 Jul 1;19(3):212.

14. Al-Jabri MM, Al-Raddadi A. Childhood vitiligo: A retrospective hospital based study, Jeddah, Saudi Arabia. Journal of the Saudi Society of Dermatology \& Dermatologic Surgery. 2011 Jan 1;15(1):15-7.

15. Liu, J-B., et al. "Clinical profiles of vitiligo in China: an analysis of 3742 patients." Clinical and Experimental Dermatology: Clinical dermatology 30.4 (2005): 327-331. 
medRxiv preprint doi: https://doi.org/10.1101/2020.09.16.20195636; this version posted September 18, 2020. The copyright holder for this

16. Zhang Z, Xu SX, Zhang FY, Yin XY, Yang S, Xiao FL, Du WH, Wang JF, Lv YM, Tang HY, Zhang XJ. The analysis of genetics and associated autoimmune diseases in Chinese vitiligo patients. Archives of dermatological research. 2009 Feb 1;301(2):167-73.

17. Ranaivo Irina Mamisoa., et al. "Childhood Vitiligo Seen in Dermatology Department of the University Hospital Joseph RasetaBefelatanana, Antananarivo, Madagascar”. EC Microbiology 15.5 (2019): 334-338.

18. Sheth PK, Sacchidan and S, Asha GS. Clinico-epidemiological profile of childhood vitiligo. Indian Journal of Paediatric Dermatology. 2015 Jan 1;16(1):23.

19. Topal IO, Gungor S, Kocaturk OE, Duman H, Durmuscan M. Nail abnormalities in patients with vitiligo. Anais brasileiros de dermatologia. 2016 Aug;91(4):442-5.

20. Lin X, Tang LY, Fu WW, Kang KF. Childhood Vitiligo in China. American journal of clinical dermatology. 2011 Aug 1;12(4):277-81.

21. Lahlou A, Baybay H, Gallouj S, Mernissi FZ. Childhood vitiligo: Clinical epidemiological profile. Our Dermatology Online. 2017 Jul 1;8(3):264.

22. Al-Mutairi N, Kumar Sharma A, Al-Sheltawy M, Nour-Eldin O. Childhood vitiligo: a prospective hospital-based study. Australasian journal of dermatology. 2005 Aug;46(3):150-3.

23. Handa S, Dogra S. Epidemiology of childhood vitiligo: a study of 625 patients from north India. Pediatric dermatology. 2003 May;20(3):207-10.

24. Ference JD, Last AR. Choosing topical corticosteroids. American family physician. 2009 Jan $15 ; 79(2): 135-40$.

25. Silverberg NB, Lin P, Travis L, Farley-Li J, Mancini AJ, Wagner AM, Chamlin SL, Paller AS. Tacrolimus ointment promotes repigmentation of vitiligo in children: a review of 57 cases. Journal of the American Academy of Dermatology. 2004 Nov 1;51(5):760-6.

26. Kanwar AJ, Dogra S, Parsad D. Topical tacrolimus for treatment of childhood vitiligo in Asians. Clinical and Experimental Dermatology: Clinical dermatology. 2004 Nov;29(6):589-92. 
medRxiv preprint doi: https://doi.org/10.1101/2020.09.16.20195636; this version posted September 18, 2020. The copyright holder for this preprint (which was not certified by peer review) is the author/funder, who has granted medRxiv a license to display the preprint in perpetuity. All rights reserved. No reuse allowed without permission.

27. Kumar Y H, Rao G R. Narrow-band ultraviolet B in childhood vitiligo: An open prospective uncontrolled study in 28 children of South India. Indian J Paediatr Dermatol $2015 ; 16: 17-22$

28. Majid I, Masood Q, Hassan I, Khan D, Chisti M. Childhood vitiligo: Response to methylprednisolone oral minipulse therapy and topical fluticasone combination. Indian Journal of Dermatology. 2009 Apr;54(2):124. 